\title{
Lipoproteins and apolipoproteins in the young and familial risk of coronary atherosclerosis
}

\author{
Cuno S.P.M. Uiterwaal ${ }^{a}$, Jacqueline C.M. Witteman ${ }^{a}$, Willy-Anne H.J. van Stiphout ${ }^{a}$, \\ Xeno H. Krauss ${ }^{\mathrm{b}}$, Anthony M. de Bruijn ${ }^{\mathrm{a}}$, Albert Hofman ${ }^{\mathrm{a}}$, Diederick E. Grobbee ${ }^{\mathrm{a}, *}$

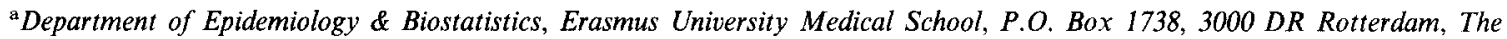 \\ Netherlands \\ ${ }^{b}$ Department of Cardiology, Zuiderziekenhuis, Rotterdam, The Netherlands
}

Received 5 April 1995; revised 27 October 1995; accepted 10 November 1995

\begin{abstract}
The aim of this study was to assess the predictive value of lipoproteins and apolipoproteins at a young age for the development of coronary artery disease at middle and older ages. Because children of coronary artery disease patients are at high risk themselves we compared lipoprotein and apolipoprotein levels between the offspring of parents with and without coronary artery disease. We selected a group of male patients $(n=90)$, who had severe coronary atherosclerosis at angiography, and a reference group of male controls $(n=62)$, who had no coronary atherosclerosis at angiography. Lipoprotein and apolipoprotein levels were determined in 115 sons and 73 daughters of the patients with severe coronary atherosclerosis. These were compared to levels in 68 sons and 47 daughters of controls. Additionally, lipoprotein and apolipoprotein levels were compared between patients and controls as well as between their spouses. In sons of patients, lower levels of $\mathrm{HDL}_{3}$ cholesterol $(-0.07 \mathrm{mmol} / \mathrm{l}$, standard error of the mean (SEM) $0.03, P<0.05)$ and apolipoprotein A2 $(-5.1 \mathrm{mg} / \mathrm{dl}$ (SEM, 1.4), $P<0.001)$ were found compared to sons of controls. Similar differences were observed in daughters of such patients without, however, achieving statistical significance. No significant differences between the groups of offspring were found for total cholesterol, LDL cholesterol, $\mathrm{HDL}$ and $\mathrm{HDL}_{2}$ cholesterol, triglycerides and apolipoproteins A-I and B. Patients had higher levels of total (group difference $0.6 \mathrm{mmol} / \mathrm{l}(\mathrm{SEM}, 0.18), P<0.001)$ and LDL cholesterol $(0.6 \mathrm{mmol} / \mathrm{l}(\mathrm{SEM}, 0.17), P<0.001)$, triglycerides $(0.6 \mathrm{mmol} / 1$ (SEM, 0.16), $P<0.001)$ and apolipoprotein $\mathrm{B}(21.2 \mathrm{mg} / \mathrm{dl}$ (SEM, 5.1$), P<0.001)$, and lower HDL cholesterol $(0.1 \mathrm{mmol} / \mathrm{l}$ (SEM ,0.04), $P<0.05)$ than controls. Spouses of patients had higher levels of triglycerides $(0.23 \mathrm{mmol} / 1$ (SEM, 0.11$), P<0.05)$. Our findings add to the growing evidence that predictors for athcrosclerotic disease can be detected relatively early in life. It is concluded that reduced levels of $\mathrm{HDL}_{3}$ cholesterol and apolipoprotein A2 may be early risk indicators for coronary atherosclerosis later in life.
\end{abstract}

Keywords: Apolipoproteins; Family; Coronary

* Corresponding author. Tel.: + 31104087489 ; fax: + 31104365933. 


\section{Introduction}

Coronary heart disease as well as its risk factors tend to aggregate in families [1-4]. Recent prospective studies have shown that a parental history of myocardial infarction is an independent risk factor for coronary artery disease in offspring $[5,6]$. It follows from this that children of patients with coronary heart disease are at increased risk of developing the disease at middle or older age. Early risk factors for the life-long process of atherosclerosis may therefore be identified by relating disease in parents and risk factors in their offspring. Atherosclerotic lesions that developed early in life have been shown to be related to cholesterol levels and other risk factors [7-10]. Although total serum cholesterol levels measured in adolescent men have been shown to be associated with the occurrence of manifest cardiovascular disease later in life [11], less is known about the role of lipoprotein and apolipoprotein levels in early life as risk factors for atherosclerosis later in life. The majority of family studies related risk factors in offspring to parental (history of) myocardial infarction and seem to indicate that specifically apolipoproteins B and A1 are important indicators for risk of myocardial infarction later in life [12-15].

In the present study, we examined the association between offspring risk factors and parental atherosclerosis, as assessed by angiography. We therefore studied lipoprotein and apolipoprotein levels in 188 children of male patients who suffered from severe clinically manifest and angiographically proven coronary atherosclerosis which were compared to levels measured in 115 children of male controls who did not have coronary atherosclerosis at diagnostic coronary angiography.

\section{Subjects and methods}

From 1987 to 1992, two groups of male patients were selected from the coronary angiography databases of the cardiology departments of the Zuiderziekenhuis in Rotterdam (1987-1991), the Academic Hospital Dijkzigt in Rotterdam
(1988-1989), the Refaja Ziekenhuis in Dordrecht (1990-1991), and the Antonius Hospital in Nieuwegein (1992), the Netherlands. The index group had severe coronary atherosclerosis, defined as more than $70 \%$ stenosis in at least three major coronary vessels at angiography (patients). A reference group had no or only minor angiographic lesions, defined as $20 \%$ stenosis or less in all coronary vessels (controls). Additional criteria for both groups of men were: (1) age between 45 and 65 years, (2) blood pressure not exceeding $160 / 100 \mathrm{mmhg}$, (3) absence of liver disease, diabetes mellitus, thyroid disease, and renal disease, (4) coronary angiography within 2 years preceding examination, (5) first consultation of a physician for cardiac complaints within 5 years preceding examination for this study. Eligible subjects were sent a letter in which they, their children and spouse were invited to participate in the study. Spouses of patients and controls were included in the study to enable distinction between a paternal-offspring and a maternal-offspring origin of offspring group differences in lipid profiles. The average time elapsed since catheterisation to the present examination was $12.6 \pm 6.0$ months (mean \pm S.D.) for patients and $13.6 \pm$ 6.4 months for controls.

\subsection{Measurements}

The patients, spouse, sons and daughters were asked to come to the hospital at $09: 00 \mathrm{~h}$ after fasting for at least $12 \mathrm{~h}$. Systolic blood pressure (SBP) and diastolic blood pressure (DBP) were measured using a random zero sphygmomanomcter (Hawksley). Fasting serum blood samples were drawn by antecubital venipuncture for measurement of triglycerides, total cholesterol, low density lipoprotein cholesterol (LDL cholesterol), high density lipoprotein cholesterol (HDL cholesterol), its subfractions $\mathrm{HDL}_{2}$ cholesterol and $\mathrm{HDL}_{3}$ cholesterol, apolipoprotein A1, apolipoprotein A2, and apolipoprotein B. Height and weight were measured without shoes and heavy clothing. The Quetelet-index was calculated as weight $(\mathrm{kg})$ divided by squared height $\left(\mathrm{m}^{2}\right)$.

The patients and controls answered a questionnaire about the number of first degree relatives 
who had suffered from myocardial infarctions and the use of medication at the time of examination (medication was taken to the hospital). Parents and children answered a questionnaire referring to a 1-month period prior to the examination, with questions on use of medication, habitual alcohol intake, coffee intake, and smoking habits. In addition, spouses and daughters were asked about the use of oral contraceptives, menstrual cycle and pregnancies. Sons and daughters were also asked about changes in lifestyle (physical activity, smoking behaviour, and fat intake) since their fathers had first been examined by a physician for cardiac complaints. In the first 50 families selected for this study all members were invited for baseline measurements only. In these families the response rate was $92 \%$. In the next 102 families, the sons ( 80 sons of patients and 57 sons of controls) were invited to come to the hospital on a separate day because of their simultaneous involvement in another study for which the criteria and conditions were similar to those in the present study. The sons as well as the daughters from these 102 families underwent the same measurements under the same conditions as the offspring of the first 50 families. The protocol of the extended study required sons from these 102 families to stay in the hospital for $12 \mathrm{~h}$, and the response rate was lower $(65 \%)$ in this group of sons.

\subsection{Laboratory analysis}

Serum total cholesterol was measured with an automated enzymatic method, using the Boehringer Mannheim (FRG) CHOD-PAP reagent kit [16]. HDL and LDL cholesterol were measured by the same method after precipitation. For HDL cholesterol, the phosphotungstate method according to Burstein et al. [17] was used with a minor modification as described by Grove [18]. For LDL cholesterol, precipitation was carried out with polyvinylsulphate (Boehringer Mannheim, FRG). Throughout the entire study period the results of both total cholesterol and HDL cholesterol were within limits of the quality control programme of the WHO Regional Lipid Reference Centre (Prague, Czechoslovakia). Apolipoproteins A1 and B were assayed by an automated immunoturbidimetric method (Kone Diagnostics, Espoo, Finland). Apolipoprotein A2 was determined by radial immunodiffusion against specific antiserum (Boehringer Mannheim, FRG) according to Cheung and Albers, with slight modifications [19]. All automated analyses were carried out on the Kone Specific Analyzer (Kone Instruments, Espoo, Finland) using frozen $\left(-20^{\circ} \mathrm{C}\right)$ serum samples. $\mathrm{HDL}_{2}$ and $\mathrm{HDL}_{3}$ cholesterol subfractions in serum were assayed as described by Gidez et al. [20] with slight modifications.

Table 1

Characteristics of patients, controls and their spouses

\begin{tabular}{lcccc}
\hline & $\begin{array}{l}\text { Patients } \\
(n=90)\end{array}$ & $\begin{array}{l}\text { Controls } \\
(n=62)\end{array}$ & $\begin{array}{l}\text { Spouses of patients } \\
(n=91)\end{array}$ & $\begin{array}{l}\text { Spouses of controls } \\
(n=61)\end{array}$ \\
\hline Age (years) & $56.4 \pm 7.6$ & $52.2 \pm 8.1^{* *}$ & $52.5 \pm 9.4$ & $49.2 \pm 7.9^{*}$ \\
Height (cm) & $175.6 \pm 6.0$ & $178.6 \pm 7.9^{*}$ & $166.3 \pm 6.1$ & $166.2 \pm 6.4$ \\
Weight (kg) & $78.5 \pm 8.7$ & $79.8 \pm 11.0$ & $72.4 \pm 12.5$ & $71.4 \pm 10.3$ \\
Quetelet-index (kg/m $\left.{ }^{2}\right)$ & $25.4 \pm 2.2$ & $25.0 \pm 2.9$ & $26.2 \pm 4.5$ & $25.9 \pm 3.9$ \\
SBP (mmHg) & $127.2 \pm 12.8$ & $127.5 \pm 16.9$ & $127.0 \pm 16.7$ & $125.3 \pm 14.8$ \\
DBP (mmHg) & $84.1 \pm 11.1$ & $82.1 \pm 10.3$ & $83.6 \pm 11.1$ & $81.0 \pm 8.3$ \\
Current smoking (\%) & 18.9 & 21.0 & 18.7 & $36.1^{*}$ \\
Alcohol intake (g/day) & $13.8 \pm 13.6$ & $14.1 \pm 11.4$ & $6.4 \pm 7.7$ & $6.7 \pm 8.0$ \\
Coffee drinking (\%) & 98.9 & 93.5 & 97.8 & 98.4
\end{tabular}

Values are means \pm S.D., unless stated otherwise; SBP, systolic blood pressure; DBP, diastolic blood pressure.

${ }^{*} P<0.05 ;{ }^{* *} P<0.01 ;{ }^{* *} P<0.001$ for differences between patients and controls and their spouses. 
Table 2

Characteristics of sons and daughters of patients and controls

\begin{tabular}{lcccc}
\hline & $\begin{array}{l}\text { Sons of patients } \\
(n=115)\end{array}$ & $\begin{array}{l}\text { Sons of controls } \\
(n=68)\end{array}$ & $\begin{array}{l}\text { Daughters of patients } \\
(n=73)\end{array}$ & $\begin{array}{l}\text { Daughters of controls } \\
(n=47)\end{array}$ \\
\hline Age (years) & $25.5 \pm 6.4$ & $22.5 \pm 5.6^{* *}$ & $25.4 \pm 8.3$ & $21.4 \pm 7.7^{* *}$ \\
Height (cm) & $180.8 \pm 9.7$ & $181.3 \pm 11.3$ & $167.0 \pm 7.5$ & $167.6 \pm 9.9$ \\
Weight $(\mathrm{kg})$ & $75.8 \pm 12.9$ & $73.8 \pm 13.3$ & $63.7 \pm 11.5$ & $60.1 \pm 14.0$ \\
Quetelet-index (kg/m $\left.{ }^{2}\right)$ & $23.0 \pm 2.9$ & $22.3 \pm 3.1$ & $22.9 \pm 4.0$ & $21.2 \pm 3.8^{*}$ \\
SBP (mmHg) & $122.9 \pm 13.4$ & $118.2 \pm 14.5^{*}$ & $113.5 \pm 14.5$ & $116.0 \pm 11.2$ \\
DBP (mmHg) & $79.4 \pm 10.1$ & $73.9 \pm 12.7^{* *}$ & $74.3 \pm 11.0$ & $72.5 \pm 8.4$ \\
Current smoking (\%) & 33.9 & 29.4 & 37.0 & $19.1^{*}$ \\
Alcohol intake (g/day) & $11.6 \pm 12.9$ & $9.3 \pm 9.6$ & $4.8 \pm 6.0$ & $5.6 \pm 6.4$ \\
Coffee drinking (\%) & 82.6 & 73.5 & 75.3 & $51.1^{* *}$ \\
Post menarche (\%) & - & - & 92.8 & 84.1 \\
Pregnant at examination & - & - & 2.9 & 7.1 \\
(\%) & - & 43.5 & 45.2 \\
Usc of oral contraceptives & - & & & \\
(\%) & & & & \\
\hline
\end{tabular}

Values are means \pm S.D., unless stated otherwise; SBP, systolic blood pressure; DBP, diastolic blood pressure.

${ }^{*} P<0.05 ;{ }^{* *} P<0.01 ;{ }^{* * *} P<0.001$ for differences between sons and daughters of patients and controls.

$\mathrm{HDL}_{2}$ and $\mathrm{HDL}_{3}$ cholesterol subfractions were separated using stepwise precipitation of apolipoprotein B containing lipoproteins with heparin/ $\mathrm{Mn}^{2+}$ in two steps and $\mathrm{HDL}_{2}$ with dextran-sulphate.

\subsection{Statistical methods}

Mean values and standard deviations were calculated for all characteristics of the patients and controls, and their spouses, sons and daughters, separately. Mean group differences in baseline characteristics were tested with the $t$-test or Mann-Whitney $U$-test when appropriate, and the $\chi^{2}$-test for proportional data. All further analyses were adjusted for age. Adjusted mean values for lipoproteins levels in parents and offspring were obtained using linear regression analysis with the (apo)lipoprotein level as the dependent and a group indicator and age as the independent variables. Because of the dependency of measurements between brothers and between sisters within families, group differences between lipoprotein values in the offspring were analyzed using a repeated measures analysis of variance where patients and controls were considered the sampling units (BMDP, 1990). In this analysis, lipoprotein values in sons and daughters were considered repeated measures within families. In the repeated measures analysis mean lipoprotein levels were adjusted for age, as well as for a combination of age, height, weight, systolic blood pressure, diastolic blood pressure, smoking, alcohol intake and in daughters, the use of oral contraceptives. The associations between (apo)lipoprotein levels in family members were assessed by linear regression analysis of patients and controls, their spouses, and the first sons or daughters taking part in the study.

\section{Results}

Table 1 shows the characteristics of the patients and the controls, as well as their spouses. Only the group differences in smoking in spouses remained statistically significant after adjustment for age.

Table 2 gives the characteristics for sons and daughters of patients and controls. After adjustment for age only the group differences in diastolic blood pressure in sons remained statistically significant.

In Table 3, the mean (apo)lipoprotein levels are given for patients and controls and their spouses. 
Table 3

Lipoprotein and apolipoprotein levels in patients and controls and their spouses

\begin{tabular}{lcccc}
\hline & $\begin{array}{l}\text { Patients } \\
(n=90)\end{array}$ & $\begin{array}{l}\text { Controls } \\
(n=62)\end{array}$ & $\begin{array}{l}\text { Spouses of patients } \\
(n=91)\end{array}$ & $\begin{array}{l}\text { Spouses of controls } \\
(n=61)\end{array}$ \\
\hline TC $(\mathrm{mmol} / \mathrm{l})$ & $6.9(0.11)$ & $6.3(0.14)^{* * *}$ & $6.6(0.2)$ & $6.6(0.18)$ \\
LDL-C $(\mathrm{mmol} / 1)$ & $5.1(0.11)$ & $4.5(0.13)^{* * *}$ & $4.6(0.15)$ & $4.8(0.19)$ \\
HDL-C $(\mathrm{mmol} / \mathrm{l})$ & $1.1(0.03)$ & $1.2(0.04)^{*}$ & $1.4(0.03)$ & $1.3(0.03)$ \\
$\mathrm{HDL}_{2}-\mathrm{C}(\mathrm{mmol} / \mathrm{l})$ & $0.2(0.01)$ & $0.2(0.02)$ & $0.4(0.03)$ & $0.3(0.02)$ \\
HDL $3^{-C}(\mathrm{mmol} / \mathrm{l})$ & $0.9(0.02)$ & $0.9(0.02)$ & $1.1(0.03)$ & $1.0(0.02)$ \\
TG $(\mathrm{mmol} / \mathrm{l})$ & $2.09(0.09)$ & $1.50(0.12)^{* * *}$ & $1.48(0.08)$ & $1.25(0.06)^{*}$ \\
Apo A1 $(\mathrm{mg} / \mathrm{dl})$ & $133.5(2.5)$ & $135.6(3.8)$ & $155.0(3.5)$ & $145.2(3.8)$ \\
Apo A2 $(\mathrm{mg} / \mathrm{dl})$ & $45.3(0.8)$ & $46.6(0.8)$ & $47.3(0.7)$ & $47.1(0.9)$ \\
Apo B $(\mathrm{mg} / \mathrm{dl})$ & $131.4(3.3)$ & $110.2(3.7)^{* * *}$ & $111.0(3.6)$ & $106.0(3.5)$ \\
\hline
\end{tabular}

Values are means (SEM), adjusted for age; TC, total cholesterol; LDL-C, low density lipoprotein cholesterol; HDL-C, high density lipoprotein cholesterol; TG, triglycerides; Apo, apolipoprotein.

${ }^{*} P<0.05 ;{ }^{* *} P<0.01 ;{ }^{* *} P<0.001$ for differences between patients and controls and their respective family members.

As expected, there were considerable differences with regard to lipids and apolipoproteins between the patients and controls. Further adjustment for other risk factors did not materially change these results (data not shown). In the spouses the only difference was a higher triglyceride level in the spouses of patients and a higher apolipoprotein A1 after adjustment for other risk factors.

Table 4 shows the mean age adjusted lipoprotein and apolipoprotein values for the sons and differences between the two groups of sons for lipoprotein and apolipoprotein levels, as analyzed with repeated measures analysis of variance. Sons of patients on average had adverse lipoprotein and apolipoprotein levels compared with sons and daughters of controls with significantly lower levels of $\mathrm{HDL}_{3}$ cholesterol and of apolipoprotein $\mathrm{A} 2$.

Table 5 shows lipoprotein and apolipoprotein levels for daughters of patients and controls with lower $\mathrm{HDL}_{3}$ cholesterol and apolipoprotein A2 levels in daughters of patients, but only reached borderline statistical significance. An additional repeated measures analysis in which all families were excluded if either one or both parents and one or more offspring had total cholesterol levels exceeding $300 \mathrm{mg} / \mathrm{dl}$, yielded similar results. Exclusion of families in which one of the parents had a total cholesterol level exceeding $300 \mathrm{mg} / \mathrm{dl}$ still gave similar results with significantly lower levels of. $\mathrm{HDL}_{3}$ cholesterol and apolipoprotein $\mathrm{A} 2$ in sons of patients.

Fig. 1 gives the associations for total cholesterol and apolipoprotein A1 among family members. Statistically significant associations were found for total cholesterol except between fathers and spouses and sons and daughters. For LDL cholesterol and apolipoprotein B similar associations were observed. The strongest associations were found for apolipoprotein A1. Between fathers and mothers associations were observed for $\mathrm{HDL}_{3}$ cholesterol $(b=0.25,95 \% \mathrm{CI} 0.12,0.39)$ and apolipoprotein $\mathrm{A} 1(b=0.43,95 \% \mathrm{CI} 0.32,0.55)$. Much weaker or no associations between family members were observed for the other lipoproteins.

We assessed the effects of possible changes in lifestyle, possibly advised to patients, which may have been passed on to the children. There were no differences between the two groups of sons with regard to changes in reported smoking behaviour, alcohol intake and fat intake after their fathers had been first examined for cardiac complaints. However, $39 \%$ of daughters of patients reported to have diminished their fat intake, as opposed to $17 \%$ of daughters of controls (Yates corrected $\chi^{2}$ 5.1, $P=0.02$ ). Life-style advise given to patients may be assumed to have more influence on offspring living at home than offspring living separately from their parents. Therefore, an additional analysis was performed in the offspring living separately from their parents, which showed lower levels of $\mathrm{HDL}_{3}$ cholesterol 
Table 4

Differences in lipoprotein and apolipoprotein levels in the sons of patients and controls

\begin{tabular}{|c|c|c|c|c|c|}
\hline & $\begin{array}{l}\text { Sons of patients } \\
(n=115)\end{array}$ & $\begin{array}{l}\text { Sons of controls } \\
(n=68)\end{array}$ & Adjusted for & Difference & $P$-value \\
\hline \multirow[t]{2}{*}{$\mathrm{TC}(\mathrm{mmol} / \mathrm{l})$} & $5.4(0.11)$ & $5.0(0.10)$ & Age & $0.11(0.15)$ & 0.46 \\
\hline & & & Age, risk factors ${ }^{\mathrm{a}}$ & $0.0005(0.16)$ & 0.99 \\
\hline \multirow[t]{2}{*}{ LDL-C (mmol/1) } & $3.7(0.11)$ & $3.3(0.10)$ & Age & $0.14(0.15)$ & 0.36 \\
\hline & & & Age, risk factors & $0.09(0.16)$ & 0.57 \\
\hline \multirow[t]{2}{*}{ HDL-C (mmol/1) } & $1.2(0.02)$ & $1.2(0.03)$ & Age & $-0.04(0.05)$ & 0.43 \\
\hline & & & Age, risk factors & $-0.07(0.05)$ & 0.12 \\
\hline \multirow[t]{2}{*}{$\mathrm{HDL}_{2}-\mathrm{C}(\mathrm{mmol} / \mathrm{l})$} & $0.2(0.01)$ & $0.2(0.02)$ & Age & $0.02(0.03)$ & 0.35 \\
\hline & & & Age, risk factors & $0.005(0.03)$ & 0.86 \\
\hline \multirow[t]{2}{*}{$\mathrm{HDL}_{3}-\mathrm{C}(\mathrm{mmol} / \mathrm{l})$} & $0.9(0.02)$ & $1.0(0.02)$ & Age & $-0.07(0.03)$ & 0.048 \\
\hline & & & Age, risk factors & $-0.09(0.04)$ & 0.007 \\
\hline \multirow[t]{2}{*}{$\mathrm{TG}(\mathrm{mmol} / \mathrm{l})$} & $1.16(0.06)$ & $1.13(0.07)$ & Age & $-0.03(0.10)$ & 0.78 \\
\hline & & & Age, risk factors & $-0.11(0.10)$ & 0.27 \\
\hline \multirow[t]{2}{*}{ Apo A1 (mg/dl) } & $126.6(2.5)$ & $123.8(2.8)$ & Age & $3.1(4.8)$ & 0.52 \\
\hline & & & Age, risk factors & $-2.8(4.5)$ & 0.54 \\
\hline \multirow[t]{2}{*}{ Apo A2 $(\mathrm{mg} / \mathrm{dl})$} & $44.1(0.6)$ & $47.5(1.3)$ & Age & $-5.1(1.4)$ & 0.0003 \\
\hline & & & Age, risk factors & $-4.4(1.3)$ & 0.0007 \\
\hline \multirow[t]{2}{*}{ Apo B (mg/dl) } & $89.4(2.5)$ & $83.9(2.5)$ & Age & $2.1(3.6)$ & 0.57 \\
\hline & & & Age, risk factors & $-0.6(3.7)$ & 0.87 \\
\hline \multirow[t]{2}{*}{ Apo Al/Apo B } & $1.6(0.04)$ & $1.5(0.06)$ & Age & $0.07(0.08)$ & 0.39 \\
\hline & & & Age, risk factors & $0.007(0.08)$ & 0.92 \\
\hline
\end{tabular}

Values are means (SEM), adjusted for age and mean differences (values sons patients - values sons controls) as calculated with repeated measures analysis of variance; $p$-values compare sons of patients with sons of controls; TC, total cholesterol; LDL-C, low density lipoprotein cholesterol; HDL-C, high density lipoprotein cholesterol; TG, triglycerides; Apo, apolipoprotein.

adjusted for risk factors: height, weight, systolic blood pressure, diastolic blood pressure, smoking, alcohol intake.

(difference $-0.07 \mathrm{mmol} / 1$ (SEM, 0.04), $P=$ $0.07)$ and apolipoprotein A2 ( $-5.5 \mathrm{mg} / \mathrm{dl}$ (SEM, $0.5), P=0.0003)$ in sons of patients. Similar results were observed in daughters of patients who had lower levels of $\mathrm{HDL}_{3}$ cholesterol $(-0.12$ $\mathrm{mmol} / 1$ (SEM, 0.05), $P=0.02$ ) and apolipoprotein A2 $(-4.5 \mathrm{mg} / \mathrm{dl}(\mathrm{SEM}, 1.9), P=0.02)$.

\section{Discussion}

In this study, sons of patients with coronary atherosclerosis had lower $\mathrm{HDL}_{3}$ cholesterol and apolipoprotein A2 levels compared to sons of controls. Daughters of patients tended to also have lower levels of $\mathrm{HDL}_{3}$ cholesterol and apolipoprotein $\mathrm{A} 2$, but these differences reached only borderline significance. No differences were found for other lipoproteins and apolipoproteins measured.
Before interpreting these findings some methodologic aspects of the study need to be discussed. The angiographical selection of patients and controls enabled us to maximize the atherosclerotic contrast between these groups, as reflected in differences in lipoprotein and apolipoprotein levels. An important advantage of studying risk factors in offspring in relation to disease in parents is that the risk factors are measured well before the manifestations of atherosclerosis. A further advantage is that although there may be differences between the patients and controls with regard to lifestyle and medication, important differences, particularly with respect to medication, will not be present in the offspring. Although a higher proportion of daughters of paticnts reported to have changed fat intake since their father's first examination for cardiac complaints, perhaps explaining group differences, this was not accompanied by a change in other aspects of lifestyle, in 
Table 5

Differences in lipoprotein and apolipoprotein levels in the daughters of patients and controls

\begin{tabular}{|c|c|c|c|c|c|}
\hline & $\begin{array}{l}\text { Daughters of patients } \\
(n=47)\end{array}$ & $\begin{array}{l}\text { Daughters of controls } \\
(n=73)\end{array}$ & Adjusted for & Difference & $P$-value \\
\hline \multirow[t]{2}{*}{$\mathrm{TC}(\mathrm{mmol} / \mathrm{l})$} & $5.6(0.14)$ & $5.0(0.15)$ & Age & $0.19(0.24)$ & 0.43 \\
\hline & & & Age, risk factors ${ }^{a}$ & $0.28(0.25)$ & 0.27 \\
\hline \multirow[t]{2}{*}{ LDL-C (mmol/l) } & $3.6(0.14)$ & $3.1(0.15)$ & Age & $0.16(0.26)$ & 0.55 \\
\hline & & & Age, risk factors & $0.24(0.25)$ & 0.34 \\
\hline \multirow[t]{2}{*}{ HDL-C (mmol/1) } & $1.5(0.04)$ & $1.5(0.04)$ & Age & $-0.005(0.06)$ & 0.87 \\
\hline & & & Age, risk factors & $-0.04(0.05)$ & 0.44 \\
\hline \multirow[t]{2}{*}{$\mathrm{HDL}_{2}-\mathrm{C}(\mathrm{mmol} / 1)$} & $0.4(0.03)$ & $0.4(0.03)$ & Age & $0.05(0.04)$ & 0.10 \\
\hline & & . & Age, risk factors & $0.06(0.04)$ & 0.09 \\
\hline \multirow[t]{2}{*}{$\mathrm{HDL}_{3}-\mathrm{C}(\mathrm{mmol} / \mathrm{l})$} & $1.1(0.02)$ & $1.1(0.03)$ & Age & $-0.05(0.04)$ & 0.27 \\
\hline & & & Age, risk factors & $-0.07(0.04)$ & 0.14 \\
\hline \multirow[t]{2}{*}{$\mathrm{TG}(\mathrm{mmol} / \mathrm{l})$} & $1.14(6.0)$ & $1.04(8.0)$ & Age & $0.09(0.12)$ & 0.46 \\
\hline & & & Age, risk factors & $0.13(0.11)$ & 0.24 \\
\hline \multirow[t]{2}{*}{ Apo Al $(\mathrm{mg} / \mathrm{dl})$} & $159.6(3.7)$ & $151.6(4.3)$ & Age & $10.6(6.4)$ & 0.10 \\
\hline & & & Age, risk factors & $11.9(6.5)$ & 0.07 \\
\hline \multirow[t]{2}{*}{ Apo $\mathrm{A} 2(\mathrm{mg} / \mathrm{dl})$} & $46.6(1.0)$ & $48.0(1.0)$ & Age & $-2.7(1.6)$ & 0.11 \\
\hline & & & Age, risk factors & $-2.1(1.6)$ & 0.21 \\
\hline \multirow[t]{2}{*}{ Apo B (mg/dl) } & $86.9(2.6)$ & $77.8(3.6)$ & Age & $5.7(5.2)$ & 0.29 \\
\hline & & & Age, risk factors & $8.1(4.8)$ & 0.09 \\
\hline \multirow[t]{2}{*}{ Apo Al/Apo B } & $1.9(0.07)$ & $2.1(0.09)$ & Age & $-0.05(0.13)$ & 0.73 \\
\hline & & & Age, risk factors & $-0.08(0.12)$ & 0.45 \\
\hline
\end{tabular}

Values are means (SEM), adjusted for age and mean differences (values daughters patients - values daughters controls) as calculated with repeated measures analysis of variance; $P$-values compare daughters of patients with daughters of controls; TC, total cholesterol; LDL-C, low density lipoprotein cholesterol; HDL-C, high density lipoprotein cholesterol; TG, triglycerides; Apo, apolipoprotein.

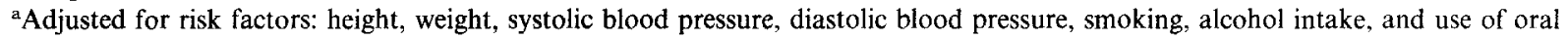
contraceptives.

particular smoking. Furthermore, as it is not likely that changes to healthier lifestyles affect lipoprotein levels unfavourably, such changes, if present, will result in an underestimation of the true differences. Support for the absence of important effects of lifestyle changes was found in the demonstration of the same differences in offspring living separately from their parents who are probably less affected by lifestyle advise given to the patients, as the total groups of offspring. A possible explanation for smaller differences between the groups of daughters is that the transmission of risk of atherosclerosis or the transmission of risk factors is more pronounced from fathers to sons than from fathers to daughters. This might have been different if female coronary artery disease patients and female controls had been sampled.
Our findings are generally in agrecment with those in other studies [21] in that the offspring of patients suffering from coronary artery disease have less favourable lipid profiles. However, studies have indicated that particularly apolipoprotein A1, apolipoprotein B, and their ratio as measured in offspring of CAD patients are more strongly related to risk of cardiovascular disease than other (apo)lipoproteins [13-15,22]. In the present study, apolipoprotein Al was somewhat higher in offspring of patients. In agreement with earlier studies were the higher apolipoprotein B levels in offspring of patients, although differences were not statistically significant. In contrast to earlier studies, we found $\mathrm{HDL}_{3}$ cholesterol and apolipoprotein A2 levels to be lower in offspring of patients. Differences in results may be explained by the fact that in the majority of the earlier 


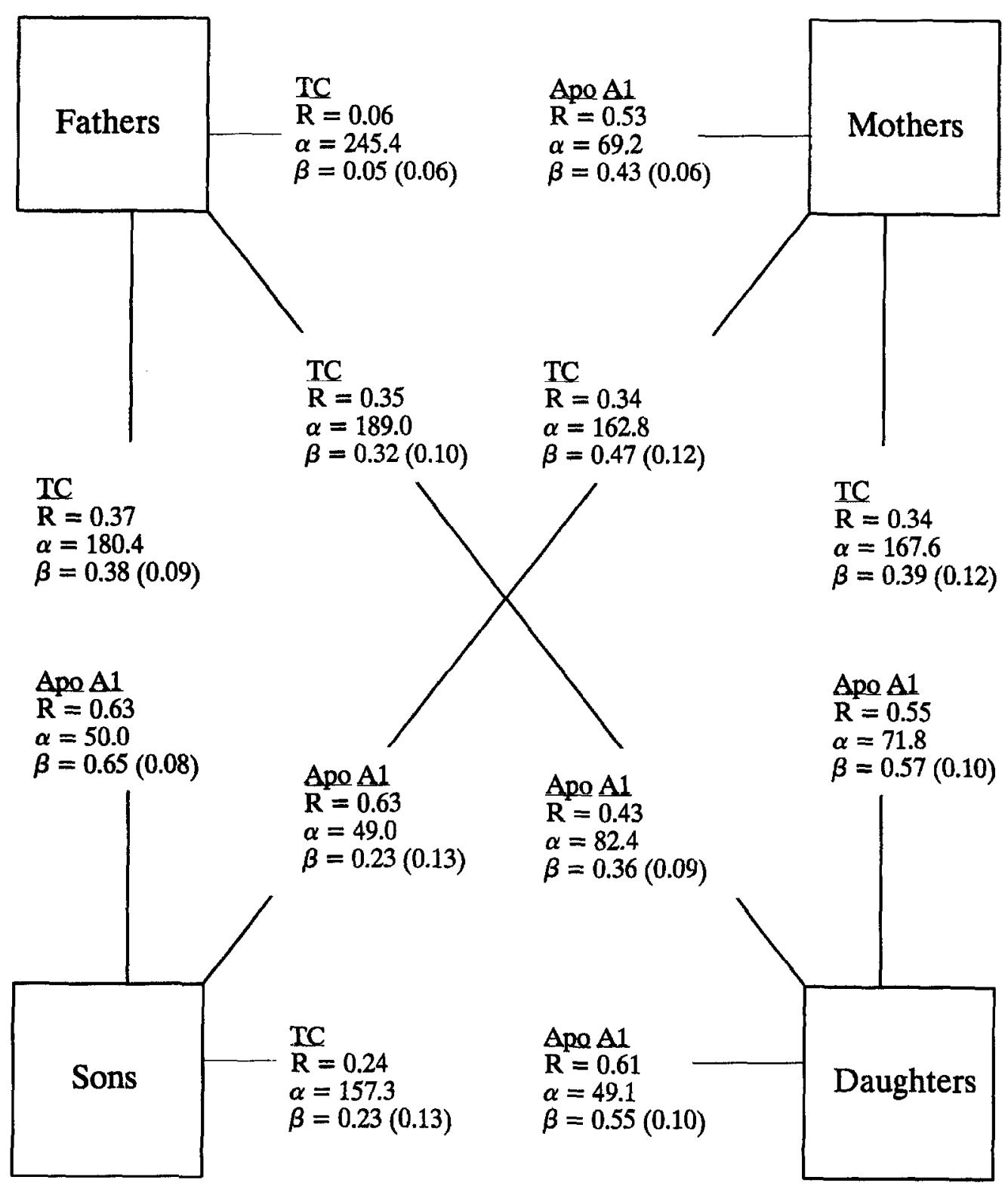

Fig. 1. TC, total cholesterol; Apo A1, apolipoprotein A1; $R$, correlation coefficient; linear regression: $\alpha$, intercept; $\beta$, regression coefficient (standard error of the mean).

studies, offspring risk factors were studied in relation to myocardial infarction in the parents [1315], while the results from the present study probably pertain more specifically to atherosclerosis. Another explanation may be that in the present study the offspring were older than in other studies [13,22].
An inverse relation between $\mathrm{HDL}$ cholesterol and risk of ischemic heart disease is well established [23-26]. HDL cholesterol levels aggregate in families of patients with myocardial infarction $[27,28]$, and HDL cholesterol subfractions and apolipoproteins $\mathrm{A} 1$ and $\mathrm{A} 2$ have been reported to be strongly and independently associated with risk 
of myocardial infarction $[29,30]$. Our results are in line with these studies and suggest that HDL cholesterol, its subfractions and related apolipoproteins play a role in atherogenesis early in life. The specific role of $\mathrm{HDL}$ subfractions $\mathrm{HDL}_{2}$ and $\mathrm{HDL}_{3}$ in the inverse relation with ischemic heart disease still has to be elucidated, although $\mathrm{HDL}_{3}$ is thought to be the most important factor in this respect. In the present study total HDL cholesterol levels are somewhat lower in sons of patients and not materially different between the two groups of daughters, and $\mathrm{HDL}_{2}$ cholesterol tends to be higher in both the sons and in daughters of patients, which is suggestive of a shift from $\mathrm{HDL}_{3}$ to $\mathrm{HDL}_{2}$ cholesterol.

In summary, we have found lower levels of $\mathrm{HDL}_{3}$ cholesterol and apolipoprotein A2 in the offspring, particularly sons, of coronary artery disease patients. Our findings add to the growing evidence that predictors for atherosclerotic disease can be detected relatively early in life. The results suggest that reduced levels of $\mathrm{HDL}_{3}$ cholesterol and apolipoprotein $\mathrm{A} 2$ may be early risk indicators for coronary atherosclerosis later in life.

\section{Acknowledgements}

The authors thank Ms Lorette O.M. Hulsman for assistance in the conduct of the study, Ms Jeanette M. Vergeer-Drop for assistance in laboratory analyses, and Dr H.J. Kingma, Antonius Hospital in Nieuwegein, Dr Ph.W. Fels, Rafaja Ziekenhuis in Dordrecht and Dr F.J. ten Cate, University Hospital Rotterdam, The Netherlands for their help in the selection of patients. This research was supported by grant no. 87058 from the Netherlands Heart Foundation and grant no. 28-1342 for the Netherlands Prevention Fund.

\section{References}

[1] Rissanen AM. Familial aggregation of coronary heart disease in a high incidence area (North Karelia, Finland). Br Heart J 1979;42:294.

[2] Friedlander Y, Bucher KD, Namboodiri KK, Heiss G, Kark JD, Tyroler HA, Eisenberg S, Stein Y, Rifkind BM. Parent-offspring aggregation of plasma lipids in selected populations in North America and Israel: The Lipid Research Clinics Prevalence Study. Am J Epidemiol 1987;126:268.

[3] Barrett-Connor E, Khaw K-T. Family history of heart attack as an independent predictor of death due to cardiovascular disease. Circulation 1984;69:1065.

[4] Criqui $\mathrm{MH}$, Barrett-Connor E, Holdbrook MJ, Austin M, Turner JD. Clustering of cardiovascular disease risk factors. Prev Med 1980;9:525.

[5] Colditz GA, Rimm EB, Giovannucci E, Stampfer MJ, Rosner B, Willett WC. A prospective study of parental history of myocardial infarction and coronary artery disease in men. Am J Cardiol 1991;67:933.

[6] Myers RH, Kiely DK, Cupples LA, Kannel WB. Parental history is an independent risk factor for coronary artery disease: The Framingham Study. Am Heart J 1990;120:963.

[7] Newman WP III, Freedman DS, Voors AW, Gard PD, Srinivasan SR, Cresanta JL, Williamson GS, Webber LS, Berenson GS. Relation of serum lipoprotein levels and systolic blood pressure to early atherosclerosis: The Bogalusa Heart Study. New Engl J Med 1986;314:138.

[8] Freedman DS, Newman WP III, Tracy RE, Voors AW, Srinivasan SR, Webber LS, Restrepo C, Strong JP, Berenson GS. Black/white differences in aortic fatty streaks in adolescence and early adulthood: The Bogalusa Heart Study. Circulation 1988;77:856.

[9] Pathobiological Determinants of Atherosclerosis in Youth (PDAY) Research Group. Relationship of atherosclerosis in young men to serum lipoprotein cholesterol concentrations and smoking. J Am Med Assoc 1990;264:3018.

[10] Berenson GS, Wattigney WA, Tracy RE, Newman WP III, Srinivasan SR, Webber LS, Dalferes ER, Strong JP. Atherosclerosis of the aorta and coronary arteries and cardiovascular risk factors in persons aged 6 to 30 years and studied at necropsy: The Bogalusa Heart Study. Am J Cardiol 1992;70:851.

[11] Klag MJ, Ford DE, Mead LA, He J, Whelton PK, Liang KY, Levine DM. Serum cholesterol in young men and subsequent cardiovascular disease. New Engl J Med 1993;328:313.

[12] Rosseneu M, Fruchart JC, Bard JM, Nicaud V, Vinaimont N, Cambien F, De Backer G. Plasma apolipoprotein concentrations in young adults with a parental history of premature coronary heart disease and in control subjects. The EARS Study. Circulation 1994;89:1967.

[13] Freedman DS, Srinivasan SR, Shear CL, Franklin FA, Webber LS, Berenson GS. The relation of apolipoproteins A-I and B in children to parental myocardial in farction. New Engl J Med 1986;315:721.

[14] De Backer G, Hulstaert F, De Munck K, Rosseneu M, Van Parijs L, Dramaix M. Serum lipids and apoproteins in students whose parents suffered prematurely from a myocardial infarction. Am Heart J 1986;112:478.

[15] Widhalm K, Koch S, Pakosta R, Schurz M, Brendinger M. Serum lipids, lipoproteins and apolipoproteins in chil- 
dren with and without familial history of premature coronary heart disease. J Am Coll Nutr 1992;11:32S.

[16] Van Gent CM, Van der Voort HA, de Bruijn AM, Klein F. Cholesterol determinations. A comparative study of methods with special reference to enzymatic procedures. Clin Chim Acta 1977;75:243.

[17] Burstein M, Scholnick HR, Morfin R. Rapid method for the isolation of lipoproteins from human serum by precipitation with polyanions. J Lipid Res 1970;11:583.

[18] Grove TH. Effect of reagent $\mathrm{pH}$ on determination of high-density lipoprotein cholesterol by precipitation with sodium phosphotungstate-magnesium. Clin Chim Acta 1979;25:560.

[19] Cheung MC, Albers JJ. The measurement of apolipoprotein A-1 and A-2 levels in men and women by immunoassay. J Clin Invest 1977;60:43.

[20] Gidez LI, Miller GJ, Burstein M, Slagle S, Eder HA. Separation and quantitation of subclasses of human plasma high-density lipoproteins by a simple precipitation procedure. J Lipid Res 1982;23:1206.

[21] Lee J, Lauer RM, Clarke WR. Lipoproteins in the progeny of young men with coronary artery disease: children with increased risk. Pediatrics 1986;78:330.

[22] Van Stiphout WAHJ, Hofman A, Kruijssen HACM, Vermeeren R, Groot PHE. Is the ratio apo B/apo A-I an early predictor of coronary atherosclerosis? Atherosclerosis $1986 ; 62: 179$.

[23] Atherosclerosis Study Group. Optimal resources for primary prevention of atherosclerotic diseases. Circulation
1984;70:157A.

[24] Heiss G, Johnson NJ, Reiland S, Davis CE, Tyroler HA. The epidemiology of plasma high density lipoprotein levels. The Lipid Research Clinics Program Prevalence Study. Circulation 1980;62(Suppl IV):116.

[25] Gordon T, Kannel WB, Castelli WB, Dawber TR. Lipoproteins, cardiovascular disease and death. The Framingham Study. Arch Intern Med 1981;141:1128.

[26] Gordon T, Castelli WP, Hjortland MC, Kannel WB, Dawber TR. High density lipoprotein as a protective factor against coronary heart disease. The Framingham Study. Am J Med 1977;62:707.

[27] Pometta D, Micheli H, Raymond L, Oberhaensli I, Suenram A. Decreased HDL cholesterol in prepubertal and pubertal children of CHD patients. Atherosclerosis 1980;36:101.

[28] Pometta D, Suenram A, Sheybani E, Grab E, James R. HDL cholesterol levels in patients with myocardial infarctions and their families. Atherosclerosis 1986;59:21.

[29] Buring JE, O'Connor GT, Goldhaber SZ, Rosner B, Herbert PN, Blum CB, Breslow JL, Hennekens CH. Decreased $\mathrm{HDL}_{2}$ and $\mathrm{HDL}_{3}$ cholesterol, apo A-I and apo A-II, and increased risk of myocardial infarction. Circulation 1991;85:22.

[30] Stampfer MJ, Sacks FM, Salvini S, Willett WC, Hennekens $\mathrm{CH}$. A prospective study of cholesterol, apolipoproteins and risk of myocardial infarction. New Engl $\mathbf{J}$ Med 1991;325:373. 